This is the peer reviewed version of the following article:

Walter Zegada-Lizarazu, Giammi Della Rocca, Mauro Centritto, Andrea Parenti, Andrea Monti

Giant reed genotypes from temperate and arid environments show different response mechanisms to drought

PHYSIOLOGIA PLANTARUM Volume 163, Issue 4, August 2018, Pages 490-501 which has been published in final form at https://doi.org/10.1111/ppl.12701

This article may be used for non-commercial purposes in accordance with Wiley Terms and Conditions for Use of Self-Archived Versions. 


\title{
Giant reed genotypes from temperate and arid environments show different response mechanisms to drought
}

\author{
Walter Zegada-Lizarazu ${ }^{a}$, Giammi Della Roccab ${ }^{b}$ Mauro Centritto ${ }^{c}$, Andrea Parenti ${ }^{a}$ and \\ Andrea Montia,* \\ aDepartment of Agricultural and Food Sciences, University of Bologna, 40127, Bologna, Italy \\ bInstitute for Sustainable Plant Protection, National Research Council of Italy, 50019, Sesto Fiorentino, Italy \\ 'Trees and Timber Institute, National Research Council of Italy, 50019, Sesto Fiorentino, Italy
}

Correspondence

*Corresponding author, e-mail: a.monti@unibo.it

\begin{abstract}
Studies at the root level and how the root-shoot interactions may influence the whole crop performance of giant reed (Arundo donax L.) under limited water conditions are largely missing. In the present study, we illustrate the effects of water stress on some phenotypic traits at the root-shoot levels of two giant reed genotypes (from Morocco and Northern Italy) that were reported to have different adaptive hydraulic stem conductivities despite the limited genetic variability of the species. The trial was carried out in $1 \mathrm{~m}^{3}$ rhizotrons $(1 \times 1 \times 1 \mathrm{~m})$ for two consecutive growing seasons. As expected, both genotypes showed an effective behavior to contrast water shortage; however, the Moroccan genotype showed a higher leaf water potential, a lower root length density (RLD) and thinner roots in the upper soil layer $(0-20 \mathrm{~cm})$, and similar to control RLD values at deep soil layers $(40-60 \mathrm{~cm})$. On the other hand the Italian genotype showed the opposite pattern; that is no drought (DR) effects in RLD and root diameter at upper soil layers and reduced RLD in deep layers, thus revealing different DR adaptation characteristics between two genotypes. This DR adaptation variability might bring new insights on DR tolerance of giant reed identifying potential traits aimed to improve the integral plant functioning, to a more efficient use of water resources, and to a more effective crop allocation to targeted stressful conditions under a climate change scenario that foresees the increase of DR periods.
\end{abstract}

\section{Introduction}

Giant reed (Arundo donax L.), a spontaneous $\mathrm{C}_{3}$ perennial rhizomatous grass, is considered one of the most promising advanced biofuel feedstock because of its high lignocellulosic yield potential in a wide range of habitats, and with low input demand (Zegada-Lizarazu et al. 2013). Ideally, giant reed should be grown in marginal land such as arid land to avoid competition against food crops and, at the same time, provide positive environmental services (Zegada-Lizarazu et al. 2013). For example, a substantial increment of soil organic carbon (about 0.7 Mg C ha-1 year $^{-1}$ ) was found in a giant reed field over a period of 16 years (Monti

Abbreviations $-\mathrm{C}_{i}$, leaf internal $\mathrm{CO}_{2}$; DAT, days after transplanting; $E$, transpiration; $\mathrm{F}_{\mathrm{v}} / \mathrm{F}_{\mathrm{m}}$, maximum quantum yield; GC-MS, gas chromatography - mass spectrometry; $g_{s}$, stomatal conductance; LAl, leaf area index; LWP, leaf water potential; $P_{n}$, photosynthesis; PPFD, photosynthetic photon flux density; RLD, root length density; RWC, relative leaf water content; SLA, specific leaf area; SWC, soil water content; $W_{i}$, intrinsic water use efficiency; WW, well-watered. 
and Zegada-Lizarazu 2016). However, its physiological adaptation mechanisms to drought (DR) remain very little known, especially at the root level. Moreover, recent studies indicated restricted variability in overall water use and $\mathrm{CO}_{2}$ gas exchange, and therefore biomass yield, in response to water stress of several giant reed genotypes (Mann et al. 2013, Nackley et al. 2014, Sanchez et al. 2015, Pompeiano et al. 2016, Romero-Munar et al. 2017, Haworth et al. 2017c). Even though such restricted variability could be related to the limited epigenetic variability among giant reed genotypes (Cosentino et al. 2006, Ahmad et al. 2008, Mariani et al. 2010, Pilu et al. 2014, Haworth et al. 2017b, 2017c), Haworth et al. (2017b) found different adaptive hydraulic stem conductivities in giant reed genotypes (the ones used in the present study) from two contrasting environments (Morocco and Northern Italy), due to the species plasticity to adapt to the prevailing climatic conditions and common abiotic stress in the respective regions of origin. Ahrar et al. (2017) also showed large DR adaptation plasticity at the photosynthetic level of Bulgarian and Italian genotypes. The magnitude of the impact of water stress among giant reed genotypes may also vary in accordance with concomitant adjustments at the roots structure and functioning levels. However, information on that regard is almost inexistent. Moreover, the different hydraulic stem conductivities found by Haworth et al. (2017b) were determined in a water-deficit study performed under pot conditions during the establishment period (i.e. first year). Hence, the potential effects of the vegetative reserve organs (i.e. rhizomes, roots, carbon and nutrient reserves) formed during the first year, on the long-term physiology and, eventually, on its deterioration with age in perennial plants (Munné-Bosch 2014, Zhou et al. 2014) are still largely unknown. To better understand the integral (root-shoot) morpho-physiological performance of giant reed under stressful conditions, it is necessary to perform studies with well-established mature plants (generally it is considered that giant reed starts its productive economic life from the second year onwards) under controlled conditions, using experimental systems that allow to simulate field conditions, with reference to planting space and soil volume (i.e. large rhizotrons). This is essential to acquire basic questions about giant reed integral DR resistance or adaptation mechanisms, as information at the root level is largely missing. Moreover, a better understanding of the species variability on the underlying physiological processes of root water uptake and $\mathrm{CO}_{2}$ assimilation dynamics would contribute in the identification of potential traits aimed to improve the plant functioning, adaptation, management and more suitable allocation to targeted stressful conditions under a climate change scenario that foresees the increase of DR periods. In particular, is still largely unknown how the root to shoot interactions effects may influence the whole crop water use dynamics, as an actively water pumping and robust wide-spreading root system is an important trait of a DR-resistant species. For example, compared to hybrid Miscanthus, switchgrass and fiber sorghum grown in rainfed conditions, giant reed showed a larger root system and higher root bulk density and is able to maintain a homogeneous water uptake along the root profile (Monti and Zatta 2009). However, root proliferation and functioning in response to water stress is not yet well documented in giant reed. Therefore, the objective of this study was to analyze the main belowground phenotypic traits (i.e. rooting patterns and water uptake dynamics) and their relationships with aboveground traits, to understand the potential DR tolerance variability in giant reed genotypes from contrasting geographical habitats.

\section{Materials and methods}

\section{Experimental setup}

Giant reed plants were grown for two consecutive years in a total of 16 rhizotrons of $1 \mathrm{~m}^{3}$ each $(1 \times 1 \times 1 \mathrm{~m})$, allowing planting spacing and soil volume available for exploration close to what is experienced under real field conditions. The rhizotrons were set up at the experimental farm of Bologna University $\left(44^{\circ} 33^{\prime} \mathrm{N}\right.$, $11^{\circ} 24.5^{\prime} \mathrm{E}$ ) in 2014 following the methodology described in Zegada-Lizarazu et al. (2012). Briefly, the rhizotrons were arranged in two parallel lines and placed under a prefabricated structure $(5 \mathrm{~m}$ in height, $50 \mathrm{~m}$ long and $5 \mathrm{~m}$ wide) covered by a polyethylene plastic film with approximately $90 \%$ of light transmission that allowed the plants to grow under natural light and ambient conditions except for rainfall (front, back and sidewalls open allowing air to flow freely and minimize any other environmental effects besides the water treatments). Each rhizotron was uniformly filled with a sandy loam soil containing $74 \%$ sand and $9 \%$ clay, collected within the farm premises, to an approximate bulk density of $1.4 \mathrm{~g} \mathrm{~cm}^{-3}$. The filled soil had a $\mathrm{pH}$ of 7.7 ; total $\mathrm{N}$, $0.64 \%$; assimilable $\mathrm{P}, 10 \mathrm{mg} \mathrm{kg}^{-1}$; exchangeable $\mathrm{K}_{2} \mathrm{O}$, $60 \mathrm{mg} \mathrm{kg}^{-1}$ and organic matter $1.0 \%$. Before both transplanting and re-sprouting, at the onset of second growing season, $100 \mathrm{~kg} \mathrm{ha}^{-1}$ of $\mathrm{N}$ and $\mathrm{P}$ were applied in each rhizotron as urea and superphosphate, respectively. The average maximum and minimum air temperatures for the experimental periods (from April to October, 2014 and 2015), measured with a portable weather station (iMetos, Pessl Instruments, Austria) were $26.0 \pm 5.6^{\circ} \mathrm{C}$ and $14.9 \pm 3.9^{\circ} \mathrm{C}$ for the 2014 growing season and 
$21.6 \pm 9.5^{\circ} \mathrm{C}$ and $11.3 \pm 6.8^{\circ} \mathrm{C}$ for the 2015 growing season, respectively. The average relative humidity was $70 \pm 13 \%$ and $74 \pm 17 \%$ in 2014 and 2015, respectively.

\section{Giant reed genotypes and treatments}

Two giant reed genotypes form contrasting environments, one from Morocco (near Marrakesh, mean annual precipitation of approximately $200 \mathrm{~mm}$ ) and the other from Northern Italy (Sesto Fiorentino, Florence, mean annual precipitation of approximately $800 \mathrm{~mm}$; Haworth et al. 2017b) were transplanted on April 22, 2014 at a density of two plants per $\mathrm{m}^{2}$. In order to reduce the heterogeneity of initial planting material, selected rhizomes of each genotype with similar number of viable buds and weight were transplanted. In each growing season, soil moisture in each rhizotron was adjusted twice a week to $23 \%$ (rhizotron water-holding capacity; considered to be the same as the field capacity of collected soil) and $10 \%(\mathrm{v} / \mathrm{v})$ in the well-watered (WW) and DR treatments, respectively. The lower limit of available water was determined as the minimum level of soil water content to support plant transpiration. The DR treatment in the first growing season started at about 40 days after transplanting (DAT) when the rhizomes of both genotypes sprouted and the stems were well-established. Those moisture content levels were maintained during the winter season and throughout the second growing season. During both growing seasons, irrigation was applied with an independent drip irrigation system per rhizotron with self-regulating emitters $\left(1.1 \mathrm{I} \mathrm{h}^{-1}\right)$ placed at $0.2 \mathrm{~m}$ intervals. The irrigation need was determined based on water deficits from the rhizotron water-holding capacity. Soil moisture content was continuously measured in the center of the rhizotrons with calibrated soil moisture probes (Spectrum S1000) installed at 0.2, 0.4 and $0.6 \mathrm{~m}$ depth and connected to automatic data loggers which recorded the readings as 6-h averages. These values were used to compute the water uptake at different depth and time intervals. Consumptive water use (evaporation and transpiration) was computed as the difference between the total water applied and the changes in soil water storage along each growing season. Root water uptake efficiency at different depth intervals was calculated as ratio between total water uptake in determined soil depths and the corresponding total root length in the soil profile.

\section{Biometric and physiological measurements}

In both growing seasons, each tiller of one plant per rhizotron was tagged in alphabetic order according to its emergence time. Then at about monthly intervals the height, basal diameter and number of green/dry leaves in each tiller per plant were determined (for clarity reasons only the final measurements are presented here). Aboveground biomass was destructively determined in the two plants per rhizotron at the end of the corresponding growing season when panicles were fully developed and plant stems stooped elongating. Dry mass was determined by oven drying to a constant weight at $105^{\circ} \mathrm{C}$. At each harvest time (October 2014 and 2015), leaf area was measured with a leaf area meter (Li-3000; LI-COR, Lincoln, NE). Water use efficiency (WUE) at plant level was defined as the ratio of aboveground dry mass produced to water loss over the corresponding growing season.

After each biometric measurement, midday gas-exchange was determined on randomly selected young fully developed leaves of the plant youngest and oldest stems using a portable IRGA (CIRAS-2; PP-Systems, UK). Photosynthesis $\left(P_{\mathrm{n}}\right)$, stomatal conductance $\left(g_{s}\right)$, leaf internal $\mathrm{CO}_{2}$ concentration $\left(C_{\mathrm{i}}\right)$ and transpiration $(E)$ were measured under $1400 \mu \mathrm{mol} \mathrm{m}^{-2} \mathrm{~s}^{-1}$ of PPFD (photosynthetic photon flux density), $390 \mu \mathrm{mol} \mathrm{mol}^{-1}$ of $\mathrm{CO}_{2}$ and $26^{\circ} \mathrm{C}$ of leaf temperature. Together with leaf gas-exchange measurements, vitality of the photosynthetic apparatus was assessed through leaf chlorophyll a florescence emissions (Handy PEA, Hansatech, UK) on alternate selected fully developed leaves from the top to the bottom of the plant youngest and oldest stems. The maximum quantum yield $\left(\mathrm{F}_{\mathrm{v}} / \mathrm{F}_{\mathrm{m}}\right)$ was measured on leaves dark-adapted for 20 min using specific leaf-clips. After the photosynthetic measurements, relative-leaf water content (RWC) was determined on leaf discs $\left(2 \mathrm{~cm}^{2}\right)$ taken from the youngest fully expanded leaves. These leaf disks were also used to determine specific leaf area (SLA, leaf area per unit dry mass) in both growing season. Furthermore, in the second growing season (2015), predawn leaf water potential (LWP) was also determined on the second fully developed leaf from the top with a pressure chamber device (PMS-670, PMS Instruments, CO, Albani, USA).

Isoprene emissions were monitored two times in each experimental season, at early and late growth stages, namely on 79 and 98 DAT in 2014 and on 429 and 512 DAT in 2015, respectively. The isoprene emission measurements were performed on four replicates per genotype and water treatment using the youngest fully developed leaf of the youngest tiller. Briefly, the measurements were performed partially diverting the outlet flow of the cuvette of a LiCor Li6400XT (Li-Cor, Inc.) equipped with light unit, containing $2 \mathrm{~cm}^{2}$ of giant reed leaf, into biphasic adsorbent traps filled with $30 \mathrm{mg}$ of Tenax and 20 mg of Carboxen (GERSTEL GmbH \& Co.KG, Mülheim an der Ruhr, Germany). The cuvette setting used was: $\left[\mathrm{CO}_{2}\right]$ of $390 \mu \mathrm{mol} \mathrm{mol}^{-1}$, PAR of $1400 \mu \mathrm{mol} \mathrm{m}^{-2} \mathrm{~s}^{-1}$ and 
leaf temperature of $26^{\circ} \mathrm{C}$. A volume of 2 I of air was pumped through the trap at a rate of $200 \mathrm{ml} \mathrm{min}^{-1}$. As blank, the concentration of isoprene in ambient air was measured using an empty leaf cuvette at the beginning and at the end of each sampling day. Isoprene was first thermally desorbed from traps and then measured by gas chromatography - mass spectrometry (GC-MS) with an Agilent HP-INNOWAX GC column as described in Haworth et al. (2017b). The isoprene molecule was identified using the NIST 11.L spectral library, while its quantification was performed using a calibration curve prepared with a commercial isoprene standard (Rivoira, Milan, Italy). The data were analyzed using the software AGILENT MASSHUNTER Workstation.

\section{Root development}

Root samplings were carried out at about monthly intervals during the first growing season, while in the second one, root samplings were taken at bimonthly intervals (here also for clarity reasons, only the final measurements are presented). Root samples were taken at $0.2 \mathrm{~m}$ intervals from the soil surface to a depth of $0.6 \mathrm{~m}$ (in agreement with the placement of the deepest soil moisture probe) with a hand-held auger (volume $392.5 \mathrm{~cm}^{3}$ ). Roots in the cores were washed out using a semiautomatic root-washing system, with $0.5 \mathrm{~mm}$ screen openings. After manually removing all debris, root samples were stored in a $70 \%(\mathrm{v} / \mathrm{v})$ ethyl alcohol solution for root's characteristics analysis. Root length and diameter were determined by image analysis of the scanned samples, after which root length density (RLD, root length per unit of soil volume) was calculated. The scanned images were acquired as bitmap files and then root length and diameter was determined using the freeware IMAGE) (https:// imagej.nih.gov/ij/).

At the end of the trial the entire plant rhizomes were dug out and carefully separated from still attached roots and debris, then fresh and dry weight were determined as in the case of aboveground dry biomass.

\section{Statistical analysis}

The experiment was laid out in a complete randomized design with four replications. Homoscedasticity of data was checked by the Bartlett's test prior ANOVA. Afterward the effects on productivity, plant growth, rooting patterns and water uptake of DR stress and genotype were evaluated using a two factor ANOVA. Whereas the effects of DR stress, genotype and plant age on the LWP and isoprene emissions were examined using a three-way ANOVA. When ANOVA revealed significant differences $(P \leq 0.05)$, the pairwise comparison Tukey's tests (HSD) was used to separate means into statistically different groups. In addition to these ANOVA tests, the relationship between all the factors evaluated here was modeled using multiple linear regression relationships and Pearson correlation coefficients.

\section{Results}

\section{Aboveground biomass and rhizomes yield and biometric parameters}

Aboveground biomass yield and biometric parameters determined in the two growing seasons are presented in Table 1. In the second growing season, the Moroccan genotype showed taller plants than Italian one under WW and dry conditions $(P \leq 0.05)$ and higher basal stem diameter under WW conditions. Whereas in the first growing season the Moroccan plants were significantly taller under WW conditions only. In contrast, DR conditions did not affect the number of tillers of the 2-year old Italian genotype, while Moroccan genotype significantly reduced the tillers $(-38 \%$ than Italian one). There were no significant differences in leaf number between the two genotypes under both WW and DR conditions in either growing season. Leaf area index (LAI) was significantly reduced by DR only in the first growing season in both genotypes (Table 1). Aboveground biomass was determined at the end of the corresponding growing season when panicles were fully developed and plant stems stooped elongating. Under WW conditions, the Moroccan genotype produced during the second growing season $27 \%(P \leq 0.05)$ higher dry biomass than Italian genotype. DR caused a dramatic decrease (about $75-80 \%$ ) of aboveground dry biomass in both genotypes (Table 1). The differences in productivity between 1 - and 2-year old plants, regardless the water treatments, were minimal and probably linked to the small differences in average growing season temperatures.

As for the biomass accumulated in the rhizomes after 2 years, no significant differences were found between genotypes under either WW or DR conditions. However, the water stress treatment resulted in an average reduction across genotypes of $72 \%$ (Table 1 ).

\section{Leaf photosynthetic parameters}

Photosynthetic traits in the first year were never statistically different between genotypes under either WW or stressed conditions. Whereas in the second year some minor genotypic differences in terms of $C_{i}$ and SLA reductions due to DR were observed in the Italian and Moroccan genotypes, respectively (Table 2). In general, the DR stress treatment resulted in an average reduction of about 31 and $42 \%$ in $P_{n}, 57$ and $59 \%$ in $g_{s}$, 23 and $19 \%$ in $C_{i}$ and 45 and $63 \%$ in $E$ during the 
Table 1. Biometric parameters, LAI and biomass productivity of Moroccan and Italian giant reed genotypes under well-watered and drought conditions. Different letters in each row indicate significant differences among treatments and genotypes at $P \leq 0.05$ level. Numbers in parenthesis

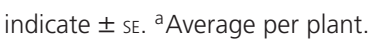

\begin{tabular}{|c|c|c|c|c|}
\hline \multirow[b]{2}{*}{ Parameter } & \multicolumn{2}{|c|}{ Well-watered } & \multicolumn{2}{|c|}{ Drought } \\
\hline & Moroccan & Italian & Moroccan & Italian \\
\hline \multicolumn{5}{|l|}{ First year } \\
\hline Stem height $(\mathrm{cm})^{\mathrm{a}}$ & $295( \pm 16)^{a}$ & $230( \pm 24)^{b}$ & $125( \pm 14)^{c}$ & $120( \pm 16)^{c}$ \\
\hline Stem diameter $(\mathrm{mm})^{\mathrm{a}}$ & $16.3( \pm 0.6)^{\mathrm{a}}$ & $14.2( \pm 0.8)^{\mathrm{a}}$ & $10.7( \pm 0.9)^{b}$ & $9.7( \pm 0.7)^{b}$ \\
\hline Number of tillers ${ }^{a}$ & $13.3( \pm 0.9)^{a b}$ & $17.8( \pm 2.9)^{a}$ & $8.5( \pm 1.5)^{b}$ & $9.5( \pm 0.9)^{b}$ \\
\hline Number of leaves ${ }^{\mathrm{a}}$ & $26.3( \pm 2.2)^{\mathrm{a}}$ & $24.7( \pm 2.6)^{\mathrm{a}}$ & $17.7( \pm 1.7)^{\mathrm{b}}$ & $19.2( \pm 2.7)^{b}$ \\
\hline LAl & $7.6( \pm 1.2)^{\mathrm{a}}$ & $8.5( \pm 1.3)^{a}$ & $2.2( \pm 0.8)^{b}$ & $2.5( \pm 0.3)^{b}$ \\
\hline Shoot biomass $\left(\mathrm{kg} \mathrm{m}^{-2}\right)$ & $5.0( \pm 0.7)^{a}$ & $4.6( \pm 0.6)^{\mathrm{a}}$ & $0.9( \pm 0.2)^{b}$ & $0.8( \pm 0.1)^{b}$ \\
\hline \multicolumn{5}{|l|}{ Second year } \\
\hline Stem height $(\mathrm{cm})^{\mathrm{a}}$ & $265( \pm 45)^{\mathrm{a}}$ & $212( \pm 23)^{b}$ & $130( \pm 43)^{c}$ & $92( \pm 20) d$ \\
\hline Stem diameter $(\mathrm{mm})^{\mathrm{a}}$ & $16.0( \pm 2.4)^{\mathrm{a}}$ & $13.2( \pm 1.5)^{b}$ & $11.3( \pm 2.5)^{c}$ & $9.4( \pm 1.9)^{c}$ \\
\hline Number of tillers ${ }^{\mathrm{a}}$ & $20.8( \pm 3.0)^{\mathrm{a}}$ & $21.8( \pm 2.8)^{\mathrm{a}}$ & $11.3( \pm 1.3)^{b}$ & $18.3( \pm 1.7)^{\mathrm{ab}}$ \\
\hline Number of leaves ${ }^{a}$ & $29.7( \pm 5.2)^{\mathrm{a}}$ & $26.5( \pm 3.6)^{a}$ & $22.7( \pm 6.8)^{b}$ & $19.7( \pm 5.3)^{b}$ \\
\hline LAl & $4.2( \pm 0.5)^{\mathrm{a}}$ & $3.6( \pm 0.5)^{a}$ & $3.2( \pm 0.6)^{a}$ & $3.3( \pm 0.2)^{a}$ \\
\hline Shoot biomass $\left(\mathrm{kg} \mathrm{m}^{-2}\right)$ & $4.9( \pm 0.3)^{\mathrm{a}}$ & $3.9( \pm 0.5)^{b}$ & $1.3( \pm 0.06)^{c}$ & $0.9( \pm 0.07)^{c}$ \\
\hline Rhizome biomass (kg pl. ${ }^{-2}$ ) & $1.8( \pm 0.2)^{\mathrm{a}}$ & $2.1( \pm 0.3)^{\mathrm{a}}$ & $0.5( \pm 0.3)^{b}$ & $0.6( \pm 0.1)^{b}$ \\
\hline
\end{tabular}

first and second growing seasons, respectively (Table 2). Moreover, in both growing seasons a significant hyperbolic relationship between $P_{\mathrm{n}}$ and $g_{\mathrm{s}}$ was found pooling together genotype and water treatment data with a steeper slope under droughted than under WW plants (Fig. 1). Therefore, some indications on possible overall DR stress response mechanisms of giant reed genotypes can be discussed. The relationships between $g_{s}$, $C_{i}, F_{v} / F_{m}, S L A$ and soil-water content (SWC), pooling together data from both growing seasons, are shown in Table 3. The $\mathrm{CO}_{2}$ gas exchange (i.e. $g_{s}, C_{\mathrm{i}}$ ) decreased consistently with DR, whereas the efficiency of photosystem II (maximum quantum yield) of both genotypes was highly stable as SWC decreased (Table 3). The intrinsic WUE (i.e. $W \cup E_{i}=P_{n} / g_{\mathrm{s}}$ ) also increased as the soil dried out, whereas SLA decreased (data not shown). Interestingly, the time-course of predawn LWP resulted rather different between the two genotypes under DR (Fig. 2A). On average, from 468 DAT until the end of the second growing season, LWP of the Italian genotype was 2.4 times lower than in control conditions, whereas the Moroccan genotype showed only a 1.5 times reduction with respect to WW plants (Fig. 2B). Moreover, in both genotypes photosynthetic parameters (i.e. $g_{s}, C_{i}, W \cup E_{i}$ ), were inversely related to decrements in LWP in response to water treatment, while $\mathrm{F}_{\mathrm{v}} / \mathrm{F}_{\mathrm{m}}$ was not related to LWP (Table 3). SLA resulted significantly related to LWP decrements. Finally, isoprene emission (Fig. 3) averaged across the two genotypes was significantly stimulated by DR ( $P \leq 0.05$, data not shown). More specifically, in 2014 the water shortage effect was significantly evident especially at late stages of the growing season (DAT 98). Whereas in the second growing season (2015) the DR effect was particularly evident on both giant reed genotypes on DAT 429 ( $P \leq 0.05$, Fig. 3 ). There was no difference in isoprene emission of WW plants between the two giant reed genotypes during both experimental seasons.

\section{Root growth and water uptake}

DR negatively affected RLD of the two genotypes in both growing seasons, but not exactly in the same way (Fig. 4A-C). As for the 1-year old plants, at DAT 197 genotype differences were found between 20 and $40 \mathrm{~cm}$ depth only; the RLD of the Moroccan ecotype under both water treatments was statistically similar, whereas in the case of the Italian genotype RLD was significantly reduced by DR (Fig. 4B). As for the 2-year old plants, at DAT 555 genotype differences were evident in the top and deep soil layers (0-20 and 40-60 cm depth, respectively); at the top layer the Moroccan genotype developed significantly $(P \leq 0.05)$ lower RLD in response to $D R$, while no significant differences in RLD were observed by the Italian genotype (Fig. 4A). At the deep layer (40-60), the opposite pattern was observed, with the Moroccan ecotype showing similar RLD values under both water treatments and the Italian genotype showing a statistically significant reduction due to DR of about $84 \%$ (Fig. 4C). Moreover at $20-40 \mathrm{~cm}$ depth, although both genotypes followed a similar reduction trend due to $\mathrm{DR}$, the RLD reduction in the Moroccan ecotype was about $85 \%$ compared with $53 \%$ reduction in the Italian genotype (Fig. 4B). No clear pattern was observed concerning root diameter (Fig. 4D-F): the Moroccan 
Table 2. Photosynthetic parameters, maximum quantum yield and SLA of Moroccan and Italian giant reed genotypes under well-watered and drought conditions. Different letters in each row indicate significant differences among treatments and genotypes at $P \leq 0.05$ level. Numbers in parenthesis



\begin{tabular}{|c|c|c|c|c|}
\hline \multirow[b]{2}{*}{ Parameters $^{\mathrm{a}}$} & \multicolumn{2}{|c|}{ Well-watered } & \multicolumn{2}{|c|}{ Drought } \\
\hline & Moroccan & Italian & Moroccan & Italian \\
\hline \multicolumn{5}{|l|}{ First year } \\
\hline$P_{\mathrm{n}}\left(\mu \mathrm{mol} \mathrm{m} \mathrm{m}^{-2} \mathrm{~s}^{-1}\right)$ & $20.5( \pm 2.2)^{a}$ & $21.1( \pm 2.0)^{\mathrm{a}}$ & $14.1( \pm 0.6)^{b}$ & $14.4( \pm 2.1)^{b}$ \\
\hline$g_{\mathrm{s}}\left(\mathrm{mmol} \mathrm{m} \mathrm{m}^{-2} \mathrm{~s}^{-1}\right)$ & $390( \pm 82)^{a}$ & $382( \pm 70)^{a}$ & $153( \pm 10)^{b}$ & $157( \pm 80)^{b}$ \\
\hline$\left.C_{i}(\mu \mathrm{mol} \mathrm{mol})^{-1}\right)$ & $242( \pm 23)^{a}$ & $234( \pm 18)^{a}$ & $181( \pm 6.4)^{b}$ & $178( \pm 22)^{b}$ \\
\hline$E\left(\mathrm{mmol} \mathrm{m} \mathrm{m}^{-2} \mathrm{~s}^{-1}\right)$ & $5.7( \pm 1.0)^{\mathrm{a}}$ & $5.6( \pm 0.8)^{a}$ & $3.2( \pm 0.3)^{b}$ & $2.9( \pm 1.0)^{b}$ \\
\hline $\mathrm{WUE}_{i}\left(\mathrm{mmol} \mathrm{mol}^{-1}\right)$ & $0.05( \pm 0.01)^{b}$ & $0.06( \pm 0.01)^{b}$ & $0.09( \pm 0.00)^{a}$ & $0.09( \pm 0.01)^{\mathrm{a}}$ \\
\hline $\mathrm{F}_{\mathrm{v}} / \mathrm{F}_{\mathrm{m}}$ & $0.79( \pm 0.01)^{\mathrm{a}}$ & $0.80( \pm 0.01)^{\mathrm{a}}$ & $0.81( \pm 0.00)^{\mathrm{a}}$ & $0.80( \pm 0.01)^{a}$ \\
\hline$S L^{a}$ & $103( \pm 1.9)^{a}$ & $104( \pm 2.0)^{a}$ & $96( \pm 1.4)^{b}$ & $97( \pm 2.5)^{b}$ \\
\hline \multicolumn{5}{|l|}{ Second year } \\
\hline$P_{\mathrm{n}}\left(\mu \mathrm{mol} \mathrm{m} \mathrm{m}^{-2} \mathrm{~s}^{-1}\right)$ & $16.0( \pm 1.5)^{\mathrm{a}}$ & $13.8( \pm 1.5)^{\mathrm{a}}$ & $9.2( \pm 1.3)^{b}$ & $8.1( \pm 1.5)^{b}$ \\
\hline$g_{\mathrm{s}}\left(\mathrm{mmol} \mathrm{m} \mathrm{m}^{-2} \mathrm{~s}^{-1}\right)$ & $244( \pm 37.1)^{a}$ & $204( \pm 36.3)^{b}$ & $92( \pm 12.3)^{c}$ & $86( \pm 37.1)^{c}$ \\
\hline$C_{i}\left(\mu \mathrm{mol} \mathrm{mol}^{-1}\right)$ & $229( \pm 16.2)^{a}$ & $228( \pm 17.1)^{\mathrm{a}}$ & $192( \pm 21.5)^{\mathrm{ab}}$ & $180( \pm 18.0)^{b}$ \\
\hline$E\left(\mathrm{mmol} \mathrm{m}^{-2} \mathrm{~s}^{-1}\right)$ & $4.7( \pm 0.8)^{\mathrm{a}}$ & $4.1( \pm 0.8)^{\mathrm{a}}$ & $1.7( \pm 0.2)^{b}$ & $1.5( \pm 0.8)^{b}$ \\
\hline $\mathrm{WUE}_{i}\left(\mathrm{mmol} \mathrm{mol}^{-1}\right)$ & $0.07( \pm 0.01)^{b}$ & $0.07( \pm 0.01)^{b}$ & $0.10( \pm 0.00)^{\mathrm{a}}$ & $0.09( \pm 0.01)^{a}$ \\
\hline $\mathrm{F}_{\mathrm{v}} / \mathrm{F}_{\mathrm{m}}$ & $0.75( \pm 0.03)^{\mathrm{a}}$ & $0.77( \pm 0.02)^{a}$ & $0.75( \pm 0.03)^{a}$ & $0.79( \pm 0.03)^{\mathrm{a}}$ \\
\hline$S L^{a}$ & $101( \pm 2.1)^{\mathrm{a}}$ & $100( \pm 2.0)^{\mathrm{a}}$ & $93( \pm 1.5)^{b}$ & $100( \pm 3.1)^{\mathrm{a}}$ \\
\hline
\end{tabular}


Fig. 1. Relationship between stomatal conductance $\left(g_{\mathrm{s}}, \mathrm{mmol} \mathrm{m} \mathrm{m}^{-2} \mathrm{~s}^{-1}\right)$ and assimilation rate of $\mathrm{CO}_{2}\left(P_{\mathrm{n}}, \mu \mathrm{mol} \mathrm{m} \mathrm{m}^{-2} \mathrm{~s}^{-1}\right)$ of $\mathrm{Moroccan}$ and Italian giant reed genotypes under well-watered (WW) and drought (DR) conditions.

genotype showed a significant $(P \leq 0.05)$ decrease in root diameter (approximately 27\%) in the topsoil layers $(0-20 \mathrm{~cm}$ depth) in response to DR (555 DAT) while no significant differences were observed in the Italian genotype (Fig. 4D).

Genotype differences in water uptake were also seen during the first and second growing season at specific soil depths (Fig. 5A-C): at top soil layers (0-20) significant reductions due to DR were found only in the case of the Moroccan genotype in both growing seasons (Fig. 5A). Whereas at mid-soil depths $(20-40 \mathrm{~cm})$ the 2-year old Italian genotype showed a significant reduction of $81 \%$ due to DR, while the Moroccan genotype did not show different water uptake capacities between
WW and droughted plants ( $P \leq 0.05$; Fig. 5B). From 40 to $60 \mathrm{~cm}$ depth, water uptake of two genotypes was almost identical under either WW or DR conditions (Fig. 5C). In general, root water uptake efficiency was the same under either water treatments or genotypes (Fig. 5D-F). The droughted Moroccan ecotype, however, resulted in significantly higher root water uptake efficiency (approximately 10 times) than the droughted Italian one at $20-40 \mathrm{~cm}$ depth in the second growing season (Fig. 5E).

Under DR conditions, the pooled RLD and root water uptake over the two growing seasons were significantly and positively related to $g_{s}$ (Table 4 ). In addition, root water uptake was also significantly correlated to WUEi, $C_{\mathrm{i}}$ and $\mathrm{F}_{\mathrm{v}} / \mathrm{F}_{\mathrm{m}}$ (Table 4). 
Table 3. Significance levels of the estimates of the linear regression relationship and Pearson correlation coefficients between the pooled data of either SWC or predawn LWP and stomatal conductance $\left(g_{s}\right)$, intercellular $\left[\mathrm{CO}_{2}\right]\left(C_{i}\right)$, intrinsic water use efficiency (WUEi) and maximum quantum yield $\left(\mathrm{F}_{\mathrm{v}} / \mathrm{F}_{\mathrm{m}}\right)$ of the Moroccan and Italian giant reed genotypes grown during both growing seasons under WW and DR conditions. $*$ under the $(\alpha)$ and $(\beta)$ columns indicated significant differences between treatments (WW and DR) at $P \leq 0.05$; whereas * under ' $r$ ' columns indicated the significance of the Pearson correlation coefficients.

\begin{tabular}{|c|c|c|c|c|c|c|}
\hline & \multicolumn{3}{|c|}{ SWC (v/v) } & \multicolumn{3}{|c|}{ LWP } \\
\hline & Intercept $(\alpha)$ & Slope $(\beta)$ & $r$ & Intercept $(\alpha)$ & Slope $(\beta)$ & $r$ \\
\hline \multicolumn{7}{|l|}{$g_{s}$} \\
\hline WW & 205 & 7.2 & 0.13 & 198 & 15.4 & 0.12 \\
\hline $\mathrm{DR}$ & $-133^{*}$ & $28.7^{*}$ & $0.44 *$ & $269 *$ & $-97.3 *$ & $0.90 *$ \\
\hline \multicolumn{7}{|l|}{ WUE $_{i}$} \\
\hline WW & 0.09 & -0.002 & $0.25 *$ & 0.06 & $-0.009 \mathrm{~ns}$ & 0.29 \\
\hline DR & $0.17^{*}$ & $-0.006^{*}$ & $0.40 *$ & $0.09^{*}$ & -0.007 & $0.42 *$ \\
\hline \multicolumn{7}{|l|}{$\mathrm{Ci}$} \\
\hline WW & 200 & 2.31 & $0.25 *$ & 260 & $-30.2 \mathrm{~ns}$ & $0.69 *$ \\
\hline $\mathrm{DR}$ & $128^{*}$ & $5.45^{\mathrm{ns}}$ & $0.28 *$ & $194 *$ & -1.17 & 0.02 \\
\hline \multicolumn{7}{|l|}{$\mathrm{F}_{\mathrm{v}} / \mathrm{F}_{\mathrm{m}}$} \\
\hline WW & 0.81 & -0.002 & $0.19 *$ & 0.76 & $-0.007 \mathrm{~ns}$ & 0.10 \\
\hline DR & $0.86^{\mathrm{nS}}$ & $-0.007^{\mathrm{nS}}$ & $0.29 *$ & $0.79^{\mathrm{ns}}$ & -0.018 & 0.18 \\
\hline \multicolumn{7}{|l|}{ SLA } \\
\hline WW & 118 & 1.1 & $0.29 *$ & 85.8 & $14.8 *$ & $0.73 *$ \\
\hline DR & $72.5^{*}$ & $2.5^{*}$ & $0.45 *$ & $89.8^{*}$ & 3.2 & $0.43 *$ \\
\hline
\end{tabular}

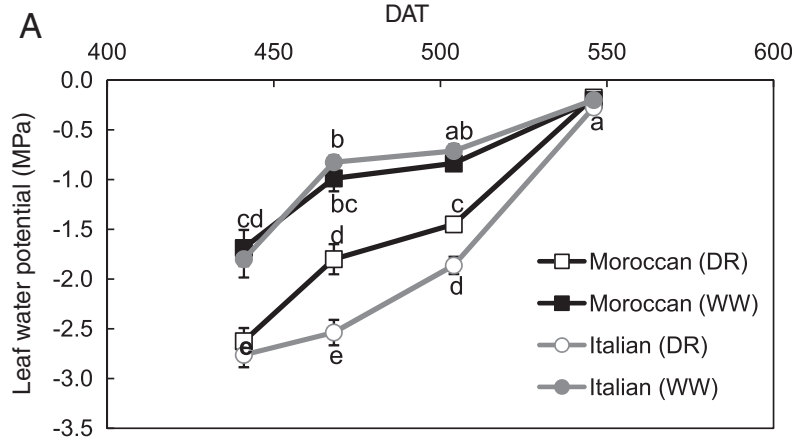

B

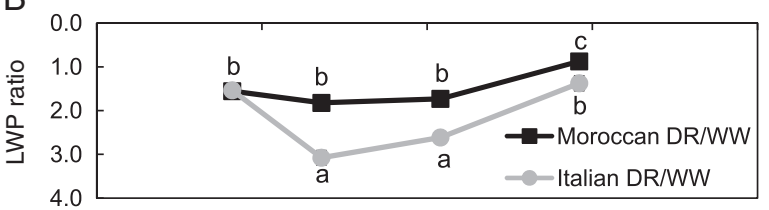

Fig. 2. Predawn LWP (MPa) and LWP ratio of droughted (DR) and WW 2-years-old Moroccan and Italian giant reed genotypes. Different letters indicate significant differences at $P \leq 0.05$ at each DAT (days after transplanting). Data are means of four plants per treatment $\pm \mathrm{SE}$.

\section{Discussion}

\section{Aboveground biomass yield, biometrical growth, and leaf physiological parameters}

DR adaptation of giant reed could be related to several factors such as phenotypic plasticity, expanded root system, persistent rhizomes and a variable accumulation capacity of carbohydrates and nutrient in the

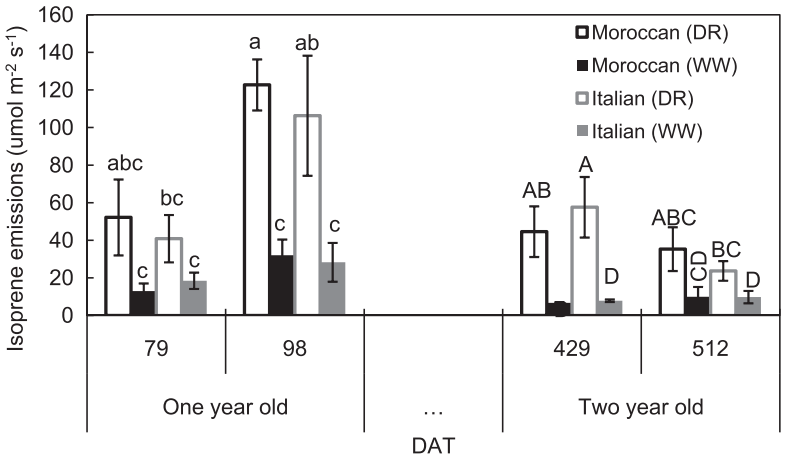

Fig. 3. Isoprene emission at early and late growth stage of Moroccan and Italian giant reed genotypes under WW and DR conditions during both experimental season. Different uppercase and lowercase letters indicate significant differences $(P \leq 0.05)$ among water treatments and genotypes at each DAT (days after transplanting) within a year. Data are means of four plants per treatment $\pm \mathrm{SE}$.

rhizomes, which, indeed, are an important emergence storage attribute of mature plants, particularly in arid environments (Mann et al. 2013). In the present study, and consistently with predictions for adaptive stress resistance, both genotypes responded to DR in a similar way by reducing shoot development and accumulating resources (carbohydrates, nutrients, water) in the rhizomes (Mann et al. 2013, Nackley et al. 2014, Table 1). However, we observed that the 2-year old Moroccan genotype produced more biomass than the Italian one under WW and DR conditions (Table 1). The higher productivity is explained by a lower number of tillers of 
A



D

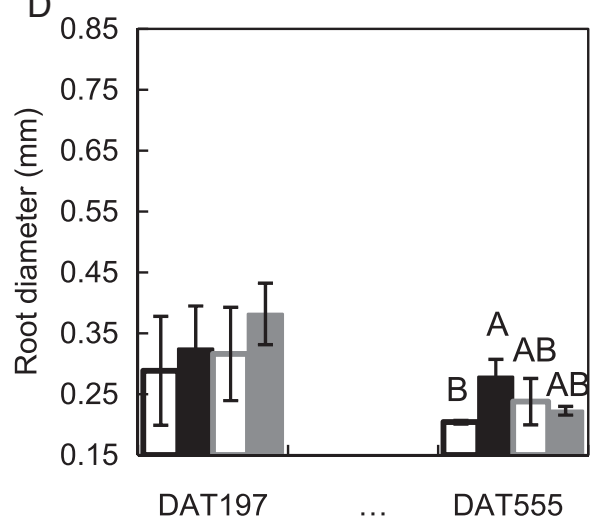

B

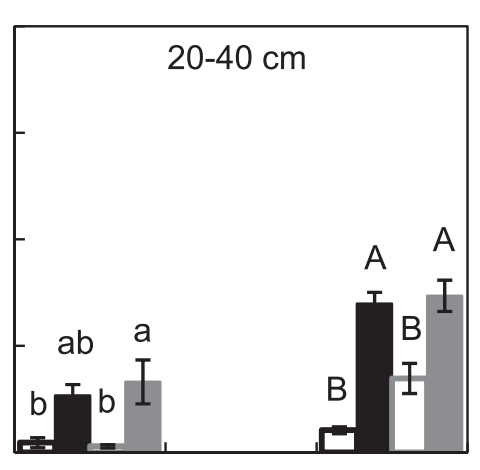

E

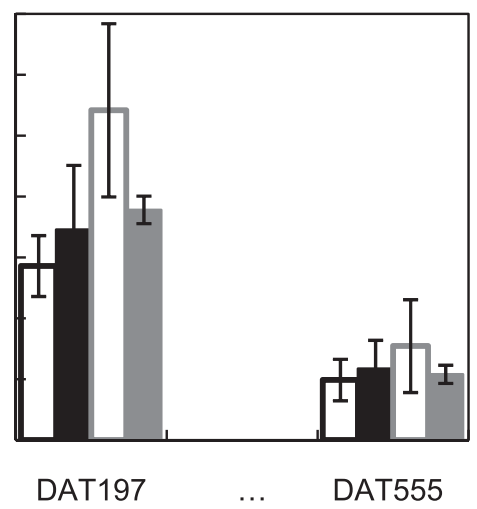

C

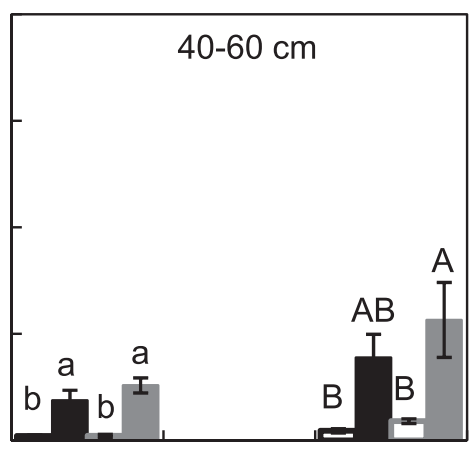

F

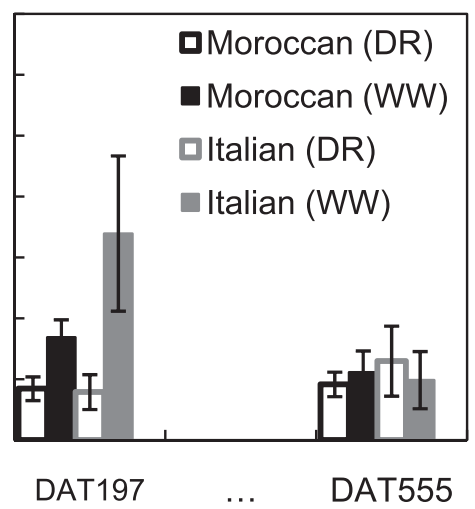

Fig. 4. RLD and root diameter of 2-year-old Moroccan and Italian giant reed genotypes under WW and DR conditions. Different uppercase and lowercase letters indicate significant differences $(P \leq 0.05)$ among water treatments and genotypes at each DAT within a year, and are shown only in the cases where significant differences were found. Data are means of four plants per treatment $\pm \mathrm{SE}$.

higher volume (i.e. height and diameter). These results suggest that a certain degree of DR adaptation variability exists in giant reed. Cosentino et al. (2006) and Pilu et al. (2014) indicated that stem height and diameter had a moderate-to-high heritability, thus they could be useful traits for clonal/provenance selection. Our findings add that stem density could be an important trait to be used in the selection of giant reed DR tolerant genotypes.

The significant higher LWP of the Moroccan genotype compared to the Italian one under DR conditions suggests that different adaptation mechanisms are adopted by two genotypes, and that those mechanisms can significantly translate into a higher biomass production $(+27 \%)$ when water shortage is an issue. LWP was directly and significantly related to $g_{s}$ and WUEi (Table 3), and hence indirectly to a higher $\mathrm{CO}_{2}$ uptake efficiency (Fig. 1 and Table 2) and possibly, as suggested by Romero-Munar et al. (2017), to a higher osmotic adjustment. Thus, the metabolic limitations to photosynthesis can be of minor importance, despite a severe LWP decrement. The Moroccan and Italian genotypes showed practically identical rates of $P_{\mathrm{n}}$ and $g_{\mathrm{s}}$ under, respectively, WW and DR conditions during both growing seasons (Table 2). As expected, the decrease in $g_{s}$ was accompanied by a decrease in $P_{\mathrm{n}}$ (Fig. 1) in a typical hyperbolic relationship fashion confirming a strong diffusive limitation to $P_{\mathrm{n}}$ under DR conditions (Nackley et al. 2014, Haworth et al. 2017a, $2017 \mathrm{~b})$. Consistently with biomass production, $P_{\mathrm{n}}$ and $g_{\text {s }}$ decreased, respectively, by 30 and 59\% with DR.

The photochemistry of both genotypes (i.e. maximum quantum yield) was highly stable as SWC decreased (Table 3), suggesting that the photochemical antenna was not damaged in water stress conditions, and that likely the excess of excitation energy (i.e. increased photosynthetic electron transport rate to photosynthesis ratio) could have been dissipated mainly through photorespiration (Wingler et al. 2000, Sun et al. 2014), and/or thermally via the xanthophylls cycle. Furthermore, the excess of excitation energy under water stress also drove to increased isoprene formation (Fig. 3) (Morfopoulos et al. 2013) that, in turn, may confer oxidative and heat stress protection (Peñuelas et al. 2005, Loreto and Schnitzler 2010). These results are in line with those found by Ahrar et al. (2017) and Haworth et al. (2017a, 2017c), which 

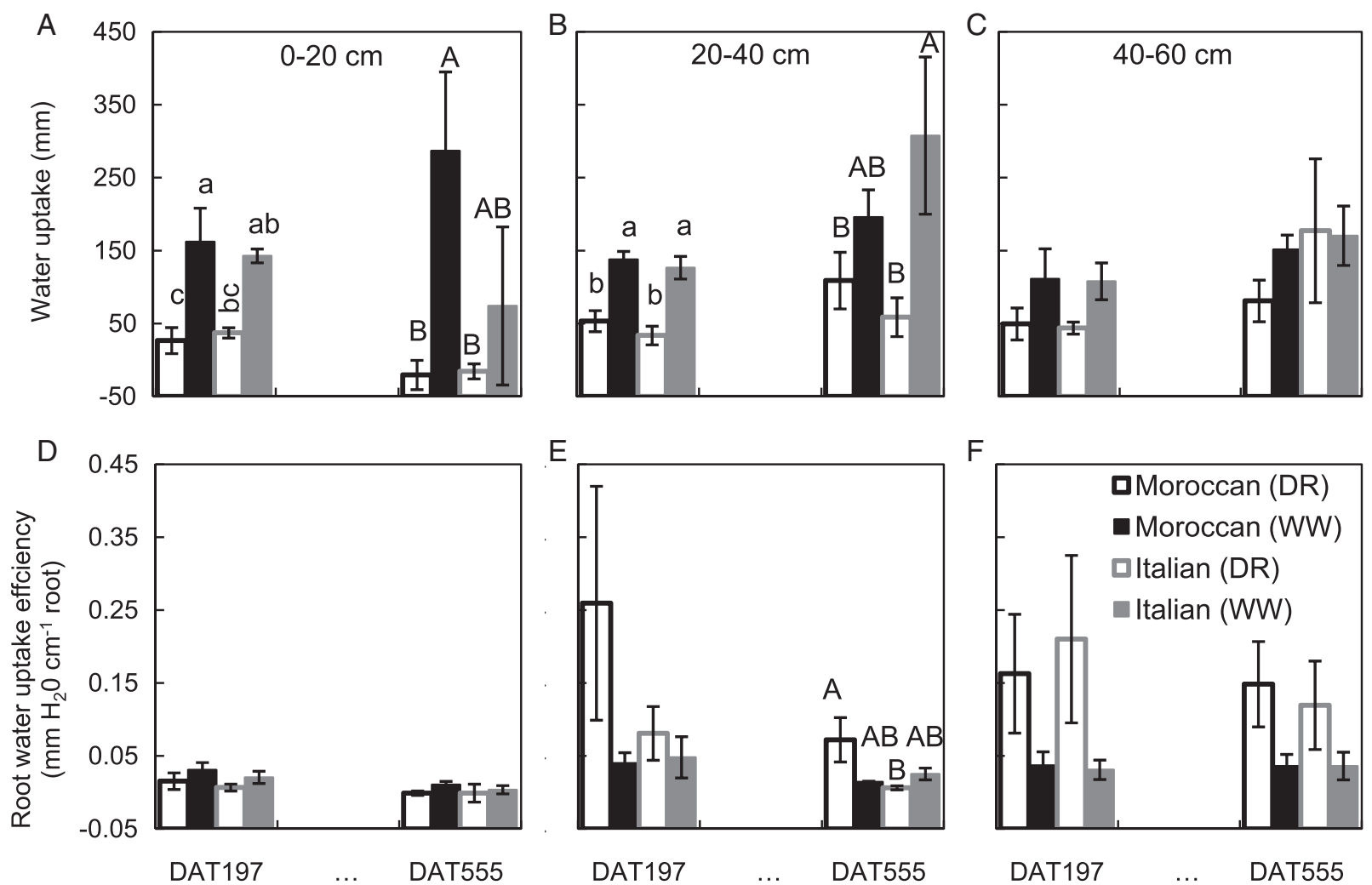

Fig. 5. Root water uptake and root water uptake efficiency of 2-year-old Moroccan and Italian giant reed genotypes under WW and DR conditions. Different uppercase and lowercase letters indicate significant differences $(P \leq 0.05)$ among water treatments and genotypes at each DAT within a year, and are shown only in the cases where significant differences were found. Data are means of four plants per treatment \pm SE.

showed that isoprene emission from different genotypes of giant reed was stimulated by water stress.

On the other hand, stem xylem vessels area and hydraulic conductance seem to be major constrains to maintain a higher water status in giant reed. Haworth et al. (2017b) found that the Moroccan genotype increased its mean stem xylem vessels area and hydraulic conductance under DR at a higher extent than the Italian giant reed genotype. Such increments would facilitate water movement from roots to leaves, allowing the plants to maintain a higher water status under DR conditions. These conclusions are supported by the better biomass performance of the Moroccan genotype (Table 1).

\section{Rooting and water uptake patterns}

During the second growing season, limited root growth due to DR was observed throughout the whole growing season and soil depths (Fig. 3), suggesting that the preferential allocation of carbohydrates to the roots may have been impaired by plant age and the water stress. In addition, the average season water uptake increased with depth differently in both genotypes in concomitance with the different rooting patterns (Figs 4 and 5): the water uptake of the droughted Moroccan genotype from 20 to $40 \mathrm{~cm}$ depth was maintained similar as in its control situation, while in the case of the Italian genotype it was maintained in the topsoil layer $(0-20 \mathrm{~cm}$ depth). Moreover, at topsoil layers the droughted Italian genotype maintained RLD statistically similar to WW plants, whereas the Moroccan genotype reduced RLD in top and middle soil layers $(0-40 \mathrm{~cm})$ in comparison to its control. In addition to that limited rhizome growth under DR was observed at the end of the trial (Table 1). Zhou et al. (2014) determined in several bermudagrass genotypes (Cynodon spp.) that rhizome mass was associated with DR resistance but it was not induced by DR stress. They hypothesized that more rhizomes could provide more resources to roots for keep higher metabolic activity. Then, the RLD and rhizome responses reported here could be seen as adaptive traits in order to reduce the metabolic cost by producing large rhizomes and shallower roots and on the other hand to increase root exploration and water uptake in deeper soil layers (Figs 4 and 5). In fact at the end of the trial the droughted 
Table 4. Significance levels of the estimates of the linear regression relationship and Pearson correlation coefficients between the pooled data of either RLD, root diameter and root or water uptake and stomatal conductance $\left(g_{s}\right)$, intercellular $\left[\mathrm{CO}_{2}\right]\left(\mathrm{C}_{i}\right)$, intrinsic water use efficiency $(\mathrm{WUE})$, maximum quantum yield $\left(F_{v} / F_{m}\right)$, and SLA of the Moroccan and Italian giant reed genotypes grown during both growing seasons under WW and DR conditions. '*' under the $(\alpha)$ and $(\beta)$ columns indicated significant differences between treatments (WW and DR) at $P \leq 0.05$; whereas '*' under ' $r$ ' columns indicated the significance of the Pearson correlation coefficients.

\begin{tabular}{|c|c|c|c|c|c|c|c|c|}
\hline & \multicolumn{4}{|c|}{ RLD } & \multicolumn{4}{|c|}{ Water uptake } \\
\hline & Intercept $(\alpha)$ & Slope $(\beta)$ & & r & Intercept $(\alpha)$ & Slope $(\beta)$ & & $r$ \\
\hline \multicolumn{9}{|l|}{$g_{\mathrm{s}}$} \\
\hline WW & $310 *$ & $-3.03 e^{-6}$ & $*$ & 0.10 & $296 *$ & -0.01 & $*$ & 0.01 \\
\hline DR & 101 & $1.78 e^{-5}$ & & $0.40 *$ & 94 & 0.46 & & $0.38 *$ \\
\hline \multicolumn{9}{|l|}{ WUEi } \\
\hline WW & $0.07 *$ & $1.14 e^{-9}$ & $*$ & 0.21 & $0.07 *$ & $-5.47 e^{-6}$ & $*$ & 0.10 \\
\hline DR & 0.11 & $-2.31 e^{-9}$ & & 0.23 & 0.12 & $-8.78 e^{-5}$ & & $0.28^{*}$ \\
\hline \multicolumn{9}{|l|}{$C_{i}$} \\
\hline WW & $233 *$ & $-1.14 e^{-6}$ & ns & 0.14 & $217 *$ & 0.02 & $*$ & 0.20 \\
\hline DR & 167 & $2.98 e^{-6}$ & & 0.18 & 160 & 0.15 & & $0.33^{*}$ \\
\hline \multicolumn{9}{|l|}{$\mathrm{F}_{\mathrm{v}} / \mathrm{F}_{\mathrm{m}}$} \\
\hline WW & $0.77 \mathrm{~ns}$ & $2.62 e^{-9} r$ & ns & $0.36^{*}$ & $0.75 *$ & $5.49 e^{-5}$ & $*$ & $0.43^{*}$ \\
\hline DR & 0.78 & $7.04 e^{-9}$ & & 0.21 & 0.77 & $2.90 e^{-4}$ & & $0.34^{*}$ \\
\hline \multicolumn{9}{|l|}{ SLA } \\
\hline WW & $104 *$ & $5.88 e^{-8} r$ & ns & 0.10 & $105 *$ & -0.001 & ns & 0.02 \\
\hline DR & 97 & $-1.56 e^{-6}$ & & 0.12 & 96 & -0.022 & & 0.12 \\
\hline
\end{tabular}

Moroccan ecotype only maintained a similar RLD in the deepest layer $(40-60 \mathrm{~cm})$ as in its control situation. In addition to that, the Moroccan ecotype hinted a reduction in the root diameter of shallower roots (Fig. 4), indicating that the Moroccan genotype probably reached a new equilibrium in the allocation of carbohydrates to the roots in the attempt to develop a better hydraulic conductivity as suggested by Haworth et al. (2017b) and, therefore, improving plant water status (Hernández et al. 2009). The better plant water status is directly indicated by the sustained LWP close to the control values (Fig. 2), the increased stomatal control (Fig. 1), and the linearly related water uptake and stomatal control under DR (Table 4) and indirectly by the taller plants and slightly higher biomass productivity of the Moroccan genotype than the Italian genotype (Table 1). Thus, in comparison to the Italian genotype, the Moroccan one may have a higher ability to maintain its deep RLD (Fig. 4) and therefore probably its root water uptake from middle-deep soil layers (i.e. $20-40 \mathrm{~cm}$; Fig. 5) in order to match the canopy water demands with the available soil water. Moreover, intra-specific differences in hydraulic conductivity at the stems xylem vessels level have been previously reported for both genotypes; with the Moroccan genotype showing an increased xylem vessel diameter and therefore a larger hydraulic conductivity (Haworth et al. 2017b).

Water potential gradients determine the passive movement of water into the roots, through the spaces between the cells (apoplasts) and/or through the cell-to-cell (symplast) pathways (Javot and Maurel
2002). Up to now, however, there is not conclusive information if one pathway predominates over the other, especially under limited soil water availability conditions. Neither information is conclusive on the associated hydraulic conductivity characteristics to each pathway. In fact, there are several studies indicating that inter-and intra-specific differences in the amounts of water moving predominantly through one of the aforementioned pathways (Steudle and Frensch 1996, Yadav etal. 1996, Steudle and Peterson 1998, Jackson et al. 2000) exist as a result of several factors. Vadez (2014) indicated that intra-specific differences in root hydraulic differences could result in a reduction of the RLD needed to fulfill the canopy water demands. In the present case, such RLD reduction (from 0 to $40 \mathrm{~cm}$ depth) seem to be operating in the case of the Moroccan genotype in contraposition to the Italian genotype where shallow RLD was maintained as in its control situations (Fig. 4). Besides that the sustained RLD at deep soil layer by the Moroccan genotype may suggest that this genotype is able to explore for water in deeper soil layers than the Italian genotype. Moreover, $g_{s}$ dependence on water uptake and RLD (Table 4) reflects a sort of balance between the plant organs that determine water loss and water uptake reached by the Moroccan genotype. Therefore, these differences may have a role to play in the DR adaptation mechanisms of giant reed genotypes.

In conclusion there is an urgent need to provide new genotypes of lignocellulosic crops able to produce sustainable biomass yields in targeted stressful production areas. The study provides additional insights 
on morpho-physiological DR adaptation mechanisms and their effects on biomass yield components of giant reed, particularly at root level. The Moroccan genotype showed more efficient adaptation mechanisms (stem height and density, leaf water status, etc.) to DR than the Italian genotype. At the root level some functional and genotype-specific DR adaptation traits began to emerge during the second growing season. As giant reed is seen as having a very low level of genetic diversity, these findings might have an interesting innovative potential for helping introduce giant reed, and more generally, for the future shaping of multifunctional agriculture in arid marginal land. An enlarged analysis of other giant reed genotypes from diverse habitat provenances might help identify other source of DR adaptation variability in giant reeds, bringing new insights on plant functioning and effective use of water and management opportunities in marginal areas.

\section{Author contributions}

W.Z.-L. designed the study, performed the experiments, analyzed data and wrote the manuscript. G.R. performed Isoprene measurements and analyzed the data. M.C. performed Isoprene analysis and writing. A.P. performed the experiments. A.M. designed the study and wrote the manuscript.

Acknowledgements - This study was funded by the EU FP7 project WATBIO (Development of improved perennial non-food biomass and bioproduct crops for water stresses environments - 311929).

\section{References}

Ahmad R, Liow PS, Spencer DF, Jasieniuk M (2008) Molecular evidence for a single genetic clone of invasive Arundo donax in the United States. Aquat Bot 88: $113-120$

Ahrar M, Doneva D, Tattini M, Brunetti C, Gori A, Rodeghiero M, Wohlfahrt G, Biasioli F, Varotto C, Loreto F, Velikova V (2017) Phenotypic differences determine drought stress responses in ecotypes of Arundo donax adapted to different environments. J Exp Bot 68: 2439-2451

Cosentino SL, Copani V, D'agosta GM, Sanzone E, Mantineo M (2006) First results on evaluation of Arundo donax L. clones collected in southern Italy. Ind Crop Prod 23: 212-222

Haworth M, Catola S, Marino G, Brunetti C, Michelozzi M, Riggi E, Avola G, Cosentino LS, Loreto F, Centritto M (2017a) Moderate drought stress induces increased foliar dimethylsulphoniopropionate (DMSP) concentration and isoprene emission in two contrasting ecotypes of Arundo donax. Front Plant Sci 8: 1016. https://doi.org/ 10.3389/fpls.2017.01016

Haworth M, Centritto M, Giovannelli A, Marino G, Proietti N, Capitani D, de Carlo A, Loreto F (2017b) Xylem morphology determines the drought response of two Arundo donax ecotypes from contrasting habitats. GCB Bioenergy 9: 119-131

Haworth M, Cosentino LS, Marino G, et al. (2017c) Physiological responses of Arundo donax ecotypes to drought: a common garden study. GCB Bioenergy 9: $132-143$

Hernández E, Vilagrosa A, Luis VC, Llorca M, Chirino E, Vallejo VR (2009) Root hydraulic conductance, gas exchange and leaf water potential in seedlings of Pistacia lentiscus L. and Quercus suber L. grown under different fertilization and light regimes. Environ Exp Bot 67: 269-276

Jackson RB, Sperry JS, Dawson TE (2000) Root water uptake and transport: using physiological processes in global predictions. Trends Plant Sci 5: 482-488

Javot H, Maurel C (2002) The role of aquaporins in root water uptake. Ann Bot 90: 301-313

Loreto F, Schnitzler JP (2010) Abiotic stresses and induced BVOCs. Trends Plant Sci 15: 154-166

Mann JJ, Barney JN, Kyser GB, Di Tomaso JM (2013) Miscanthus x giganteus and Arundo donax shoot and rhizome tolerance of extreme moisture stress. GCB Bioenergy 5: 693-700

Mariani C, Cabrini R, Danin A, Piffanelli P, Fricano A, Gomarasca S, Soave C (2010) Origin, diffusion and reproduction of the giant reed (Arundo donax L.): a promising weedy energy crop. Ann Appl Biol 157: 191-202

Monti A, Zatta A (2009) Root distribution and soil moisture retrieval in perennial and annual energy crops in Northern Italy. Agric Ecosyst Environ 132: 252-259

Monti A, Zegada-Lizarazu W (2016) Sixteen-year biomass yield and soil carbon storage of giant reed (Arundo donax L.) grown under variable nitrogen fertilization rates. Bioenergy Res 9: 248-256

Morfopoulos C, Prentice IC, Keenan TF, Friedlingstein P, Medlyn BE, Peñuelas J, Possell M (2013) A unifying conceptual model for the environmental responses of isoprene emissions from plants. Ann Bot 112: $1223-1238$

Munné-Bosch S (2014) Perennial roots to immortality. Plant Physiol 166: 720-725

Nackley LL, Vogt KA, Kim S-H (2014) Arundo donax water use and photosynthetic responses to drought and elevated $\mathrm{CO}_{2}$. Agric Water Manag 136: 13-22

Peñuelas J, Llusiá J, Asensio D, Munné-Bosch S (2005) Linking isoprene with plant thermotolerance, antioxidants and monoterpene emission. Plant Cell Environ 28: 278-286 
Pilu R, Cassani E, Landoni M, Badone FC, Passera A, Cantaluppi E, Corno L, Adani F (2014) Genetic characterization of an Italian giant reed (Arundo donax L.) clones collection: exploiting clonal selection. Euphytica 196: 169-181

Pompeiano A, Remorini D, Vita F, Guglielminetti L, Miele S, Morini S (2016) Growth and physiological response of Arundo donax L. to controlled drought stress and recovery. Plant Biosyst 2: 1-9

Romero-Munar A, Baraza E, Cifre J, Achir C, Gulías J (2017) Leaf plasticity and stomatal regulation determines the ability of Arundo donax plantlets to cope with water stress. Photosynthetica 55: 1-9

Sanchez E, Scordia D, Lino G, Arias C, Cosentino S, Nogues S (2015) Salinity and water stress effects on biomass production in different Arundo donax L. clones. Bioenergy Res 8: 1461-1479

Steudle E, Frensch J (1996) Water transport in plants: role of the apoplast. Plant Soil 187: 67-79

Steudle E, Peterson CA (1998) How does water get through roots? J Exp Bot 49: 775-788

Sun P, Wahbi S, Tsonev T, Haworth M, Liu S, Centritto M (2014) On the use of leaf spectral indices to assess water status and photosynthetic limitations in Olea europaea L. during water-stress and recovery. PLos One 9: e105165. https://doi.org/10.1371/journal.pone.0105165
Vadez V (2014) Root hydraulics: the forgotten side of roots in drought adaptation. Field Crop Res 165: 15-24

Wingler A, Lea PJ, Quick WP, Leegood RC (2000) Photorespiration: metabolic pathways and their role in stress protection. Philos Trans R Soc Lond B Biol Sci 355: 1517-1529

Yadav R, Flowers TJ, Yeo AR (1996) The involvement of the transpirational bypass flow in sodium uptake by highand low-sodium transporting lines of rice developed through intravarietal selection. Plant Cell Environ 19: 329-336

Zegada-Lizarazu W, Zatta A, Monti A (2012) Water uptake efficiency and above- and belowground biomass development of sweet sorghum and maize under different water regimes. Plant Soil 351: 47-60

Zegada-Lizarazu W, Parrish D, Berti M, Monti A (2013) Dedicated crops for advanced biofuels: consistent and diverging agronomic points of view between the USA and the EU-27. Biofuel Bioprod Bior 7: $715-731$

Zhou Y, Lambrides CJ, Fukai S (2014) Drought resistance and soil water extraction of a perennial C4 grass: contributions of root and rhizome traits. Funct Plant Biol 41: 505-519 